\title{
Overexpression of the opioid growth factor receptor downregulates cell proliferation of human squamous carcinoma cells of the head and neck
}

\author{
PATRICIA J. McLAUGHLIN ${ }^{1}$, MICHAEL F. VERDERAME ${ }^{2}$, JODY L. HANKINS ${ }^{1}$ and IAN S. ZAGON ${ }^{1}$ \\ Departments of ${ }^{1}$ Neural and Behavioral Sciences and ${ }^{2}$ Medicine, The Milton S. Hershey Medical Center, \\ The Pennsylvania State University College of Medicine, Hershey, PA 17033, USA
}

Received October 10, 2006; Accepted November 24, 2006

\begin{abstract}
The opioid growth factor (OGF) is a constitutively expressed negative growth regulator whose action is mediated by the OGF receptor (OGFr). The OGF-OGFr axis tonically regulates the growth of human squamous cell carcinoma of the head and neck (SCCHN). To examine the repercussions of amplifying OGFr in SCCHN, constructs were prepared to overexpress OGFr in SCC-1 cells; six clonal lines were examined. OGFr binding assays of clonal cells revealed a 2.4- to 8.4-fold increase in binding capacity compared to wild-type (WT) and empty vector (EV) controls; binding affinity was comparable in all groups. OGFr protein expression, as measured by quantitative immunohistochemistry and Western blotting, was increased in clonal cell lines compared to controls. Under standard growth conditions the cell number of the OGFr clonal lines was reduced by 11 to $68 \%$ from the WT group, and doubling times were 7 to $67 \%$ longer. Addition of exogenous OGF further reduced (8 to $37 \%$ ) cell growth of the clonal lines. Depletion of endogenous OGF with antibodies to this peptide increased growth 2-fold in cells amplifying OGFr relative to increases of 32 and $34 \%$ for the WT and EV groups, respectively. DNA synthesis of cells overexpressing OGFr was reduced from the WT group by 46 to $75 \%$. These data indicate that the OGF receptor is integral to cell replication of SCCHN, and support treatment modalities that amplify OGFr in order to decrease the growth of these neoplasias.
\end{abstract}

\section{Introduction}

Head and neck carcinoma of the oral cavity, pharynx, and larynx accounts for $3 \%$ of new cancer cases and $1.4 \%$ of

Correspondence to: Dr Patricia J. McLaughlin, Department of Neural and Behavioral Sciences, H109, The Milton S. Hershey Medical Center, The Pennsylvania State University College of Medicine, 500 University Drive, Room C3727, Hershey, PA 17033, USA

E-mail: pxm9@psu.edu

Key words: opioid growth factor receptor, squamous cell carcinoma of the head and neck, opioids, transfection, DNA synthesis cancer deaths annually in the United States (1). Worldwide, head and neck cancers occur in more than 500,000 individuals each year, making it the sixth most common cancer globally, and seventh in mortality (275,000 deaths) (2). Over $90 \%$ of head and neck carcinomas are squamous cell carcinomas (SCCHN) (3). The survival rate for SCCHN of the oral cavity has improved slightly in the past several decades, but the rate for SCCHN of the larynx has remained the same (1).

The opioid growth factor (OGF), chemically termed $\left[\mathrm{Met}^{5}\right]$-enkephalin, is an endogenous opioid peptide that is an important regulator of the growth of SCCHN (4-19). OGF is a constitutively expressed native opioid that is autocrine produced and secreted, and interacts with the OGF receptor (OGFr) to inhibit the growth of SCCHN and epithelial cells in vivo and in vitro $(5,7,12,14,15,18,20,21)$. The action of OGF is tonic, stereospecific, reversible, non-cytotoxic and non-apoptotic inducing, not associated with differentiative processes, independent of serum, anchorage-independent, and occurs at physiologically relevant concentrations in a wide variety of SCCHN that includes poorly- and welldifferentiated human cell lines $(5,6,11,13,17,18)$. The only opioid peptide, natural or synthetic, known to influence the growth of SCCHN is OGF (5). The action of this opioid in these neoplasias is targeted to DNA synthesis $(5,7,18)$ and is directed toward the $G_{0} / G_{1}$ interface of the cell cycle $(7,18)$, specifically the cyclin-dependent inhibitory kinase pathways (18). OGF activity in nude mice with transplanted SCCHN is receptor mediated (12), tonic and constitutive (12), and independent of the route of drug administration (14). The combination of biotherapy with OGF and chemotherapy with paclitaxel or carboplatin has proven to enhance antitumor effectiveness beyond either agent alone $(15,16)$.

The gene for human OGFr is at least $9 \mathrm{~kb}$ in length, consists of seven exons and six introns, and encodes a 677amino acid protein that includes 7 imperfect repeats of 20 amino acids each and a bipartite nuclear localization signal (NLS) $(8,9)$. OGFr has an apparent mass of $62 \mathrm{kDa}$. The chromosomal location of the human OGFr is $20 \mathrm{q} 13.3(8,9)$. Although OGFr has characteristics of a classical opioid receptor (recognizes opioids, naloxone reversibility, and stereospecificity), there is no homology of OGFr with classical opioid receptors at the nucleotide or amino acid level (9). Antisense experiments with OGFr and continuous 
blockade of opioid receptors by the potent opioid antagonist naltrexone (NTX) reveal that the OGF-OGFr axis is a tonically active inhibitory system targeted to cell replication and homeostasis, and is ligand dependent for function $(8,9)$. OGFr is localized in the outer nuclear envelope, nucleus, and perinuclear cytoplasm $(22,23)$, and OGFr binding activity has been observed in SCCHN both in vitro and in vivo $(4-6,10,12,19)$. Gene expression $(8,9,19)$ and protein expression $(4,5,12,19)$ of OGFr in SCCHN has been documented, revealing the autocrine nature of this growth regulatory peptide. Exogenous administration of OGF has a profound antitumor action on xenografts of SCCHN that includes delaying tumor appearance and reducing tumor size $(12,14,15,19)$. Evidence has been published that OGFr may be defective in SCCHN, either as a primary or secondary pathway for this disease (10). This disruption of OGFr action may be due to translational or posttranslational regulation, but is apparently not at the transcriptional level (10).

In this study, we have queried whether the amplification of OGFr signaling in SCCHN contributes to phenotypic changes, such as the loss of cell replication, which could be associated with malignant progression. To this end, we used a tissue culture model of the UM-SCC-1 cell line (SCC-1) derived from a well-differentiated recurrent squamous cell carcinoma in the floor of the mouth, and examined the effect of overexpressing OGFr on cell proliferation. The results show for the first time that molecular overexpression of the OGF receptor decreases cell replication and DNA synthesis of SCCHN cells in tissue culture, indicating that OGFr is vital in the inhibitory action of OGF. The data also establish the fundamental principle that OGF and its receptor OGFr form an autocrine loop to regulate the growth of these neoplasias, and suggest development of molecular and pharmacological strategies for the treatment of SCCHN.

\section{Materials and methods}

Human tumor line. The SCC-1 (UM-SCC-1) cell line was derived from a well-differentiated recurrent squamous cell carcinoma in the floor of the mouth of a 73-year-old male that had received radiation treatment (24). This cell line was obtained from The University of Michigan, Cancer Research Laboratory (Dr. Thomas E. Carey, Director). Cells were grown in Dulbecco's modified Eagle's medium DMEM supplemented with $10 \%$ fetal calf serum, $1.2 \%$ sodium bicarbonate, and antibiotics (5,000 Units/ml penicillin, $5 \mathrm{mg} /$ $\mathrm{ml}$ streptomycin and $10 \mathrm{mg} / \mathrm{ml}$ neomycin). The cell cultures were maintained in a humidified atmosphere of $5 \% \mathrm{CO}_{2} / 95 \%$ air at $37^{\circ} \mathrm{C}$.

Transfection and clonal selection. SCC-1 SCCHN cells were transfected with pcDNA3.1+ vector (empty vector, EV) or with the plasmid pcDNA3.1 + huOGFr (8) in the presence of Lipofectamine 2000. Transfected cells were selected by growth in media containing G418 at $500 \mu \mathrm{g} / \mathrm{ml} ; 24$ clones were expanded and analyzed for binding capacity and growth. All clonal lines were grown in media containing G418. Based on the results of these experiments, six clones were maintained and characterized. For all experiments, wild-type cells (WT) and EV cell lines served as controls.
OGFr binding assays. Binding assays for OGFr were performed with procedures described previously (6). In brief, $\log$ phase cells were harvested and the nuclear fraction was isolated through sucrose gradient centrifugation. Binding saturation isotherms were determined by specific binding of custom-synthesized $\left[{ }^{3} \mathrm{H}\right]-\left[\mathrm{Met}^{5}\right]$-enkephalin (PerkinElmerNew England Nuclear; $41 \mathrm{Ci} / \mathrm{mmol})$. Assays were performed 4-9 times on each cell line.

Immunohistochemistry. To examine the presence of OGFr, log-phase cells from clonal lines, as well as WT cells, were grown on 22-mm round coverglasses for $72 \mathrm{~h}$. Immunohistochemistry was performed according to methods described in previous reports (5). Cells were fixed and permeabilized in $95 \%$ ethanol, followed by immersion in acetone at $-20^{\circ} \mathrm{C}$, and stored at $-20^{\circ} \mathrm{C}$ for no more than 7 days before processing. Cells were incubated with ammonium sulfate purified antiOGFr-IgG (1:250) diluted in Sorenson's phosphate buffer with $1 \%$ normal goat serum in $0.1 \%$ Triton $\mathrm{X}-100$ for $18 \mathrm{~h}$ at $4{ }^{\circ} \mathrm{C}$. Coverglasses were washed and incubated with goat antirabbit $\operatorname{IgG}(1: 100)$ conjugated to rhodamine and viewed with fluorescence microscopy. Antibodies to OGFr (I0029) were generated in the laboratory to a full-length rat OGFr fusion protein (25). This antibody stained the $62-\mathrm{kDa}$ protein of OGFr in a nuclear preparation, as well as proteolysis products of 32-, 30-, 17-, and 16-kDa of OGFr (unpublished data), and recognized $50 \mathrm{ng}$ of recombinant protein at a 1:100 dilution.

Protein isolation and Western blotting. Cell samples were isolated and nuclear preparations were separated on $12 \%$ sodium dodecyl sulfate (SDS)-polyacrylamide gel electrophoresis, and gels were electrotransferred to nitrocellulose (25). Western blotting was performed with primary antibodies to recombinant human OGFr-GST fusion protein (IO682) (1:500), or with commercially available $\beta$-actin $(1: 10,000)$ (BD Biosciences, Palo Alto, CA). Antibody IO682 detects human (and rat) OGFr at $10 \mathrm{ng}$ at a 1:100 dilution, and recognizes the $62-\mathrm{kDa}$, as well as the $32-, 30-$, $17-$, and $16-\mathrm{kDa}$ fragments of OGFr. This antibody was purified over a GST-glutathione-Sepharose 4B column. Western blots were quantitated by densitometric measure of the $62-\mathrm{kDa}$ band of OGFr. The optical density (OD) of $\beta$-actin was used to standardize the protein load.

Cell proliferation. Transfected cell lines were seeded into 6or 24-well plates, and the cell number (trypan blue exclusion staining) was determined at $24 \mathrm{~h}$ intervals over a 3-4 day period. Growth curves were generated and doubling times were calculated by nonlinear curve fitting analyses (GraphPad Prism 4.0, San Diego, CA).

Growth in the presence of OGF. To determine whether overexpression of OGFr changed the response of cells to the inhibitory pentapeptide OGF, transfected cell lines, along with WT and EV cells were grown in the presence of $5 \times 10^{-6} \mathrm{M}$ OGF for $72 \mathrm{~h}$. OGF or sterile water was added beginning $24 \mathrm{~h}$ after seeding $(=0 \mathrm{~h})$; media and compounds were replaced daily. This OGF concentration was selected based on previous evidence demonstrating the growth inhibition of SCCHN $(5,16)$. 


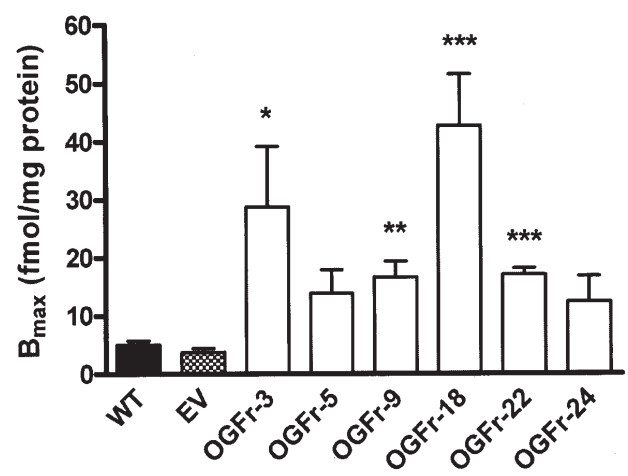

Figure 1. Binding capacity (Bmax) values for OGFr in 6 clonal cell lines overexpressing OGFr, as well as for WT and EV SCC-1 cell lines. Values represent means \pm SE for 4-9 saturation binding isotherms. Significantly different from both WT and EV at ${ }^{*} \mathrm{p}<0.05,{ }^{* *} \mathrm{p}<0.01$, and ${ }^{* * *} \mathrm{p}<0.001$.

Opioid receptor-mediated growth. To determine whether the transfected cell lines were expressing receptors that responded to pharmacological characteristics, such as blockade by opioid antagonists, transfected cells lines, along with WT and EV cell lines were grown in the presence of $10^{-5} \mathrm{M}$ naloxone (Sigma-Aldrich, St. Louis, MO), a short-acting opioid antagonist, $5 \times 10^{-6} \mathrm{M}$ OGF, both $5 \times 10^{-6} \mathrm{M}$ OGF and $10^{-5} \mathrm{M}$ naloxone, or sterile water. Treatments began $24 \mathrm{~h}$ after seeding; media and compounds were replaced daily. Cells were counted $48 \mathrm{~h}$ after initiation of drug exposure.

Specificity of OGF to cells overexpressing OGFr. To examine the specificity of OGF in cells with amplified OGFr, transfected clonal lines along with parent SCC- 1 cells (WT), were seeded at 1000 cells/well into 96-well plates and allowed a 24-h growth period prior to the addition of drugs. The cells were exposed to $10^{-6} \mathrm{M}$ concentrations of a variety of synthetic and natural opioids, with drugs and media replaced daily. The following compounds were obtained from the indicated sources: dynorphin A1-13, ß-endorphin (porcine), endomorphin-1, endomorphin-2, [D-Pen ${ }^{2,5}$-enkephalin (DPDPE), [D-Ala $\left.{ }^{2}, \mathrm{MePhe}^{4}, \mathrm{Glycol}^{5}\right]$-enkephalin (DAMGO) (Sigma, St. Louis, MO); morphine sulfate (National Institute on Drug Abuse, Rockville, MD); and U69,593 (Upjohn Pharmaceuticals, Kalamazoo, MI). The cell number was recorded at $72 \mathrm{~h}$ using the MTS proliferation bioassay (Cell Titer 96 One Solution, Promega, Madison, WI) and the absorbency was measured after $4 \mathrm{~h}$ on a BioRad (model 3550) plate reader at $490 \mathrm{~nm}$ with a $750-\mathrm{nm}$ background absorbence screening.

Effect of OGF antibody on cell proliferation. In order to determine if OGF played a role in the basal regulation of growth in cells overexpressing OGFr, clonal cell lines and WT were subjected to $1: 1000$ dilutions of anti-OGF IgG (CO-172) (22) and were counted $72 \mathrm{~h}$ later. Media and antibody were replaced daily. Previous data from our laboratory (5) demonstrated no differences in cell number between non-immune IgG-treated and control cultures.

DNA labeling indexes. To measure DNA synthesis, cells were plated onto 22-mm round coverglasses (at least 3 coverglasses/ group) and were grown in serum-containing media for $48 \mathrm{~h}$ prior to being treated with $\operatorname{BrdU}(30 \mu \mathrm{M})$ for $3 \mathrm{~h}$. Cells were stained with anti-BrdU biotin-conjugated primary antibody (1:20) (Molecular Probe/Invitrogen, Carlsbad, CA), followed by staining with goat anti-mouse HRP secondary antibody (1:1000) (Chemicon, Temecula, CA); BrdU positive cells were counted from 10 random fields and the percent labeling index was calculated. At least 1000 cells/clonal line were counted.

Statistical analysis. Cell numbers and/or absorbencies, as well as labeling indexes, were analyzed using analysis of variance (one- or two-factor where appropriate) (ANOVA) with subsequent comparisons made using the Newman-Keuls tests. Data from binding assays were subjected to analysis by GraphPad Prism, and binding affinities and capacities were generated with this computer software.

\section{Results}

Establishment and characterization of the OGFr clones. To study the effects of amplification of the OGF receptor on cell replication, several SCC-1-derived clones which overexpressed OGFr were established. To generate these clones, SCC-1 cells were stably transfected with an OGFr expression vector, and 24 neomycin-resistant clones were characterized for OGF receptor binding and growth at $72 \mathrm{~h}$ after seeding (data not shown). Six clones (OGFr-3, -5, -9, -18, -22, and -24) with different levels of OGFr expression as compared to the parental SCC-1 values, were expanded and further characterized in additional experiments (Figs. 1-6). Comparisons were made to EV and WT cell lines.

OGFr binding assays. To characterize further the SCC-1 OGFr clones, we determined the binding affinity (Kd) and binding capacity (Bmax) in these cells. Assays using radiolabeled $\left[\mathrm{Met}^{5}\right]$-enkephalin revealed specific and saturable binding for all cell lines in the study. Binding affinities did not differ between WT, EV and clonal cell lines, with $\mathrm{Kd}$ values of $3.2 \pm 0.9$ and $3.7 \pm 0.6 \mathrm{nM}$ for $\mathrm{WT}$ and $\mathrm{EV}$, respectively, and a range of $4.6 \pm 1.4$ to $9.8 \pm 2.1 \mathrm{nM}$ for the mean $\mathrm{Kd}$ levels of clonal cells.

Bmax values for clonal cells were markedly elevated from those of the WT $(5.1 \pm 0.7 \mathrm{fmol} / \mathrm{mg}$ protein $)$ and EV $(3.8 \pm 0.6 \mathrm{fmol} / \mathrm{mg}$ protein) groups, with increases ranging from 2.4- to 8.4-fold recorded in cells amplifying OGFr (Fig. 1). No difference in Bmax values between the WT and EV cell lines was noted.

The presence and distribution of OGFr protein. Immunohistochemistry preparations of two selected clonal lines, OGFr-9 and OGFr-18, grown on coverslips for $72 \mathrm{~h}$ were prepared using an antibody to OGFr. A marked increase in immunofluorescence of these two clonal cell lines relative to WT cells (Fig. 2A) and EV cells (data not shown) was observed. OGFr was localized in the cytoplasm and the nucleus in the stably transfected cell lines. Cells processed with secondary antibody only showed no staining (data not shown). Photodensitometric measurements (Fig. 2B) revealed that exposure times for clonal lines OGFr-9 and OGFr-18 were decreased by 29 and $20 \%$, respectively, from that of the 


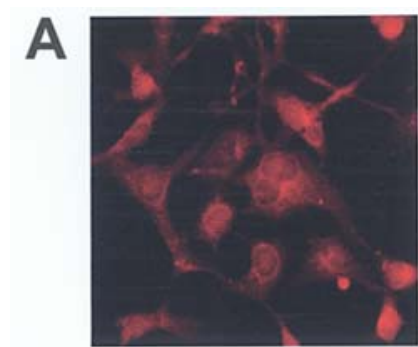

WT

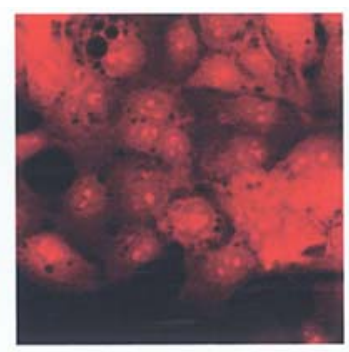

OGFr-9

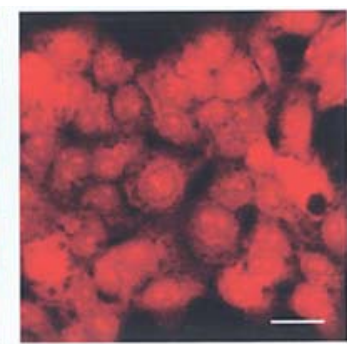

OGFr-18

B
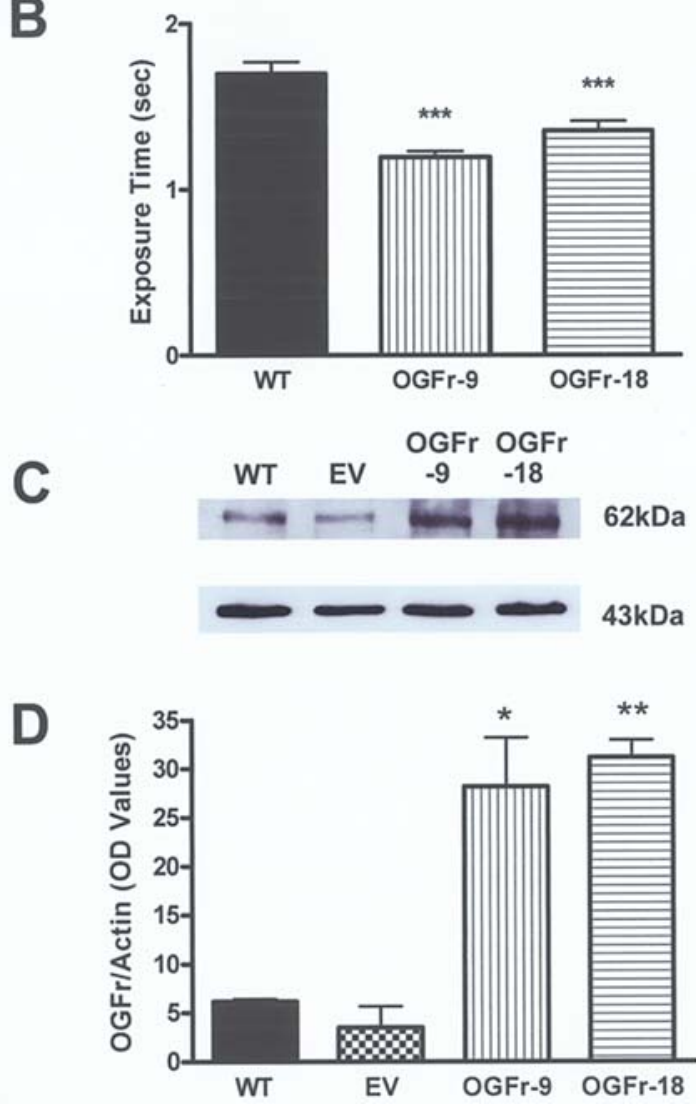

Figure 2. OGFr protein in cell lines overexpressing OGFr. (A) Immunohistochemical preparations of parent SSC-1 (WT), as well as cells overexpressing the receptor (OGFr-9 and OGFr-18), stained with an antibody to OGFr. Note the increased immunoreactivity in the specimens overexpressing OGFr. Bar, $10 \mu \mathrm{m}$. (B) Quantitation of OGFr expression in histochemical preparations using exposure time. Values represent mean \pm SE for at least 10 photodensitometric readings/group; significantly different from WT at ${ }^{* * *} \mathrm{p}<0.001$. (C) Western blot analysis of OGFr expression in SCC-1 clones, and in WT and EV cells. Levels of OGFr protein were assessed in $80 \mu \mathrm{g}$ of nuclear lysate using anti-OGFr antibody (IO682) as described in the Materials and methods. The 62-kDa band of OGFr was detected in all cell lines. Membranes were stripped and reprobed with B-actin (43 kDa) to visualize protein load. (D) Histogram of optical density ratios of OGFr/actin. Values represent means \pm SE; significantly different from WT and EV at * $\mathrm{p}<0.05$ and ${ }^{* *} \mathrm{p}<0.01$.

WT group, thereby demonstrating the overexpression of OGFr protein in these clonal cell lines.

Western blot analysis of OGFr in nuclear-enriched preparations indicated that the $62-\mathrm{kDa}$ band was present (Fig. 2C). Densitometric analysis of films revealed that the 62-kDa band of OGFr protein, standardized for loading with actin, was elevated 4.5- and 5.0-fold in clonal cell lines OGFr-9 and OGFr-18, respectively, relative to WT cells (Fig. 2D); no differences were observed between the WT and EV cells.

Cell proliferation. The functional repercussions of increasing OGFr in SCC-1 were determined by evaluating the number of cells growing in culture over a 96-h period. In general, differences between cell lines overexpressing OGFr and the
WT cultures were detected as early as $24 \mathrm{~h}$ after seeding (see Fig. 3A for a representative growth curve). Calculation of doubling times based on multiple growth curves/cell line revealed that in all but one of the clonal cell lines (OGFr-3), transfected cell lines overexpressing OGFr had increased doubling times of 16-83\% compared to EV and WT groups (Fig. 3B).

Effect of OGF antibody on cell proliferation. In order to examine the repercussion of depleting endogenous OGF in cultures of cells overexpressing OGFr, WT, EV, OGFr-9, and OGFr-22 cell lines were seeded in 96-well plates and were allowed $24 \mathrm{~h}$ before the addition of the OGF antibody CO-172; media and antibody were changed daily. At $72 \mathrm{~h}$, 
A

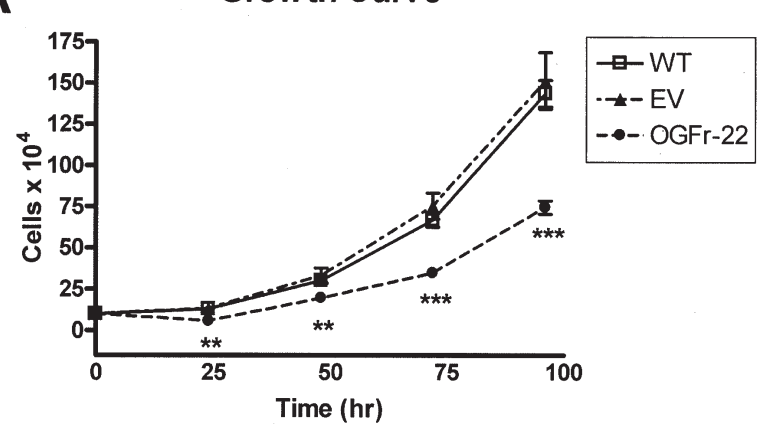

B

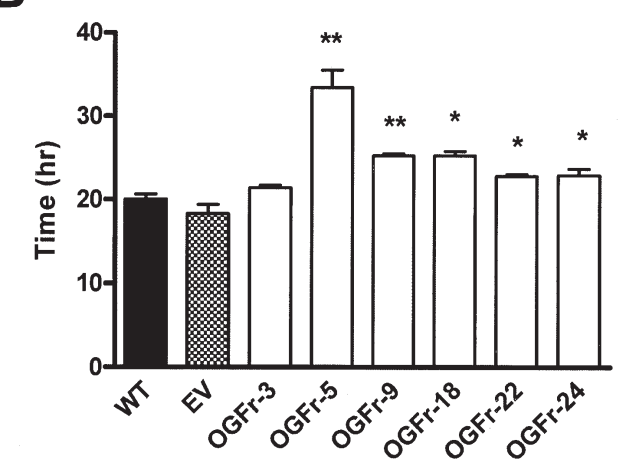

Figure 3. (A) Representative growth curves of clonal cell line OGFr-22 and $\mathrm{EV}$, as well as parental SCC-1 cells (WT). Values represent means $\pm \mathrm{SE}$ for at least 3 wells/time-point/cell line. Significantly different from WT at ${ }^{* *} \mathrm{p}<0.01$ and ${ }^{* * *} \mathrm{p}<0.001$; WT and EV did not differ from one another. (B) Doubling times in six clonal cell lines overexpressing OGFr, as well as EV and WT SCC-1 cell lines. Values were calculated from 96-h growth curves and analyzed with regression analysis. Bars, means \pm SE for 2-5 growth curves/cell line. Significantly different from WT at ${ }^{*} \mathrm{p}<0.05$ and ${ }^{* *} \mathrm{p}<0.01$; WT and EV did not differ from one another.

\section{Total Growth Inhibition Index}

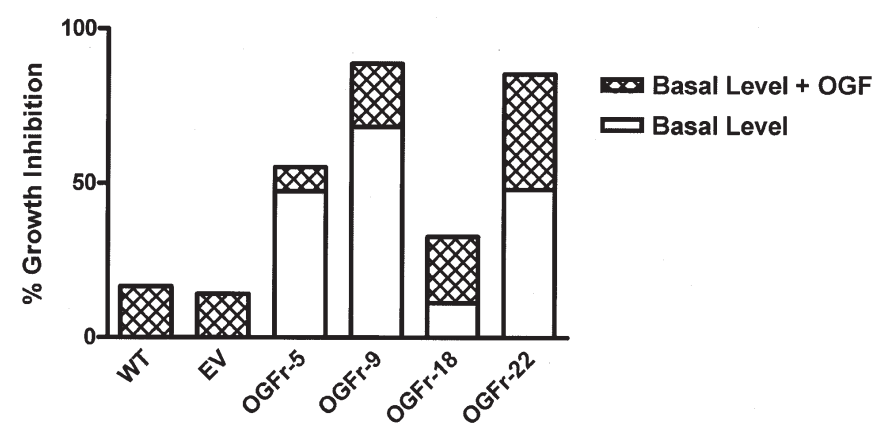

Figure 4. Total growth inhibition as determined by the sum of the percentage of decrease in cell number in clonal cell lines relative to WT cells (= basal level) after $72 \mathrm{~h}$ in culture, and the decrease in cell number following exposure of each cell line to $5 \times 10^{-6} \mathrm{M}$ OGF for $72 \mathrm{~h}$ (drugs and media were changed daily) (= basal level + OGF).

there were 32 and $34 \%$ increases in cell number for the WT and $\mathrm{EV}$ groups, respectively, but more than twice the increase (79 and 90\%) for the OGFr-9 and OGFr-22 cell lines, respectively, from basal levels.
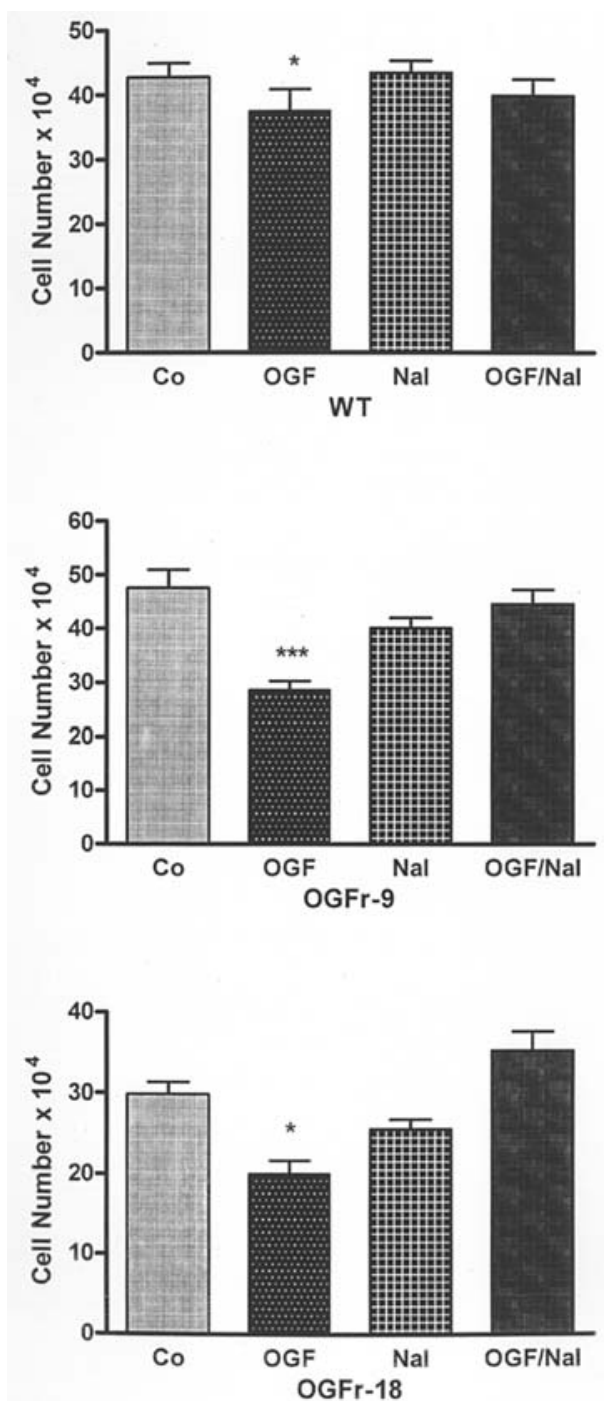

Figure 5. The number of cells in parental SCC-1, and clonal cell lines OGFr-9 and OGFr-18, following treatment for $48 \mathrm{~h}$ of OGF, OGF and naloxone (Nal), Nal, and sterile water (Co). Media and compounds were changed daily. Data represent means \pm SE for 2 aliquots/well, 3 wells/group. Significantly differently from controls at ${ }^{*} \mathrm{p}<0.05$ and ${ }^{* * *} \mathrm{p}<0.001$.

Effect of exogenous $O G F$. The addition of OGF to all cell lines (WT, EV, and clonal) depressed growth by $8-37 \%$ from their respective basal levels at $72 \mathrm{~h}$ (Fig. 4). The summation of the percent basal growth inhibition calculated from the cell number at $72 \mathrm{~h}$ with data on the percent inhibition of cell lines after exposure to OGF for $72 \mathrm{~h}$, showed a total growth inhibition of the clonal cell lines that was $200-550 \%$ greater than that for the WT and EV groups.

Opioid receptor-mediated growth. To establish whether the enhanced inhibitory effect of overexpressing OGFr in the SCC-1 cells was receptor mediated, cells were grown in the presence of the short-acting opioid antagonist naloxone (Fig. 5). Cell lines with amplified OGFr (OGFr-9 and OGFr-18) and grown in $5 \times 10^{-6} \mathrm{M}$ OGF had almost 3-fold greater decreases in cell number compared to WT. The addition of $10^{-5} \mathrm{M}$ naloxone to cultures with $5 \times 10^{-6} \mathrm{M}$ OGF, revealed that the WT, OGFr-9, and OGFr-18 cultures had cell numbers comparable to their basal levels (control). 


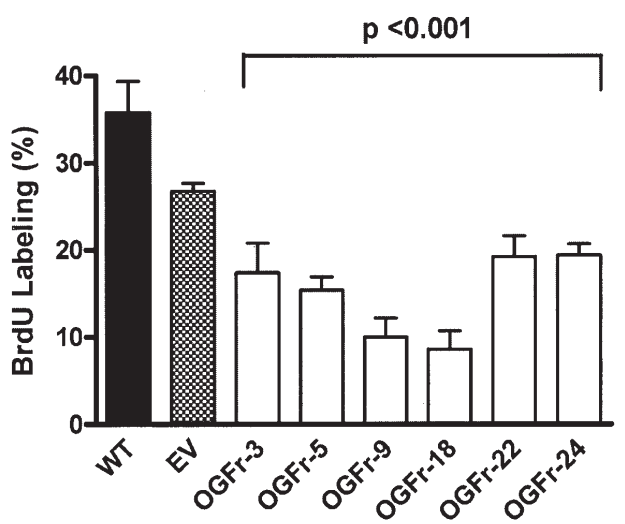

Figure 6. DNA synthesis as measured by the percentage of BrdU labeling in SCC-1 cell lines amplifying OGFr. Values represent means \pm SE for 10 fields/coverslip, and at least 2 coverslips/cell line. All transfected cell lines differed from WT and EV at $\mathrm{p}<0.001 ; \mathrm{EV}$ values were comparable to those of the WT group.

Moreover, cultures of WT, OGFr-9, and OGFr-22 cells exposed to $10^{-5} \mathrm{M}$ naloxone alone demonstrated no growth inhibition.

Specificity of OGF to cells overexpressing OGFr. Although opioid peptides other than OGF have not been found to influence the growth of SCCHN cells in culture (5), the effects of these other opioid peptides on the growth of cells overexpressing OGFr required evaluation. OGFr-9 and OGFr-18 cells were treated daily with $10^{-6} \mathrm{M}$ concentrations of a variety of natural and synthetic opioid ligands; in some cases, many of these ligands were specific for $\mu, \delta$, or $\kappa$ opioid receptors. Morphine, DAMGO, DPDPE (d-Pen,d-Penenkephalin), dynorphin 1-13, endomorphin-1, endomorphin-2, $\mathrm{U} 69,593$, and B-endorphin were not found to alter the growth of either clonal cell line or the parental (WT) cells (data not shown).

DNA labeling indexes. In comparison to the labeling index of WT cells $(35.8 \pm 3.6 \%)$, all of the clonal cell lines overexpressing OGFr were 46-76\% reduced in the number of cells incorporating BrdU (Fig. 6). Cells in the EV and WT groups were similar in the number of labeled cells.

\section{Discussion}

This study is the first to report the successful stable transfection of the OGF receptor, with resulting translation of OGFr protein, in a cancer cell line. Receptor binding assays of clonal cell lines using OGF as a radiolabeled ligand showed 2- to 8-fold more receptors in these cells than in wild-type or empty vector cell lines. The molecular and cellular nature of the amplified OGFr, however, was unchanged with respect to binding affinity, permitting an understanding of the biological effects from increasing the number of OGF receptors. Qualitative and quantitative immunohistochemical staining of OGFr in the clonal cell lines revealed a substantial increase of this receptor protein in these cells compared to wild-type and empty vector cell lines. Thus, the additional OGF receptors could be verified at the structural level. Protein expression of OGFr also was increased as measured by Western blotting with an antibody specific to this receptor. It should be noted that wild-type and empty vector cell lines were similar in all experiments (e.g., protein levels and receptor binding), arguing that the vector itself was not a confounding influence. Moreover, the selection and characterization of six clonal cell lines ensured that the characteristics of transfection of OGFr were not an isolated observation in one clonal cell line.

This report reveals for the first time that overexpression of the OGF receptor has marked repercussions on the proliferation and DNA synthesis of SCCHN cells. All clonal lines had decreased DNA synthesis of at least $50 \%$ compared to the parental line or empty vector. Moreover, doubling times of all SCC-1 cells transfected with OGFr cDNA were notably increased from those of wild-type and empty vector cells. Four of the clonal cell lines examined exhibited 11 to $68 \%$ decreases in cell number relative to either the parental cell line or empty vector, indicating that the overexpression of OGF receptors altered the basal level of cellular duplication. These results are consistent with previous reports that the OGF-OGFr axis is targeted to cyclin-dependent inhibitory kinases (18). This would suggest that the equilibrium in cell replication is disturbed by the addition of more OGF receptors, with the net result being an exaggeration in growth inhibition and a decrease in cell number. The sensitivity of cellular events to the addition of OGF receptors could also be observed when exogenous OGF was added to the cultures, and the clonal cell lines had even further reductions (8-37\% from the wild-type and empty vector) in growth. Thus, the downstream mechanism of action of OGFr is capable of responding to additional OGFr signals. In addition, the effects of exogenous OGF on cells with amplified receptors were receptor mediated as demonstrated by the neutralization of OGF action with naloxone. Finally, the total growth inhibition of clonal cell lines with respect to the summation of basal levels and addition of exogenous OGF, decreased cell number by 32 to $88 \%$ compared to wild-type and empty vector cell lines exposed to OGF. These data indicate that the introduction of OGFr cDNA into these neoplastic cells has dramatic effects on cell proliferation by activating the OGFOGFr inhibitory axis.

Examination of the data revealed that receptor number alone could not be used as a predictor of growth effects. For example, one clonal cell line that had 8.4-fold more receptors than wild-type cells displayed an $11 \%$ decrease in basal growth, whereas another clonal cell line had a 3.3-fold increase in binding capacity but a $68 \%$ decrease in cell number. Thus, although the integrity of OGFr was intact based on binding experiments and protein levels, other factors (e.g., nucleocytoplasmic transport) appeared to be at work in determining the magnitude of functional repercussions. However, placing this clonal variation aside, it should be emphasized that all of the cell lines with increased OGF receptors had marked alterations in cell replication.

In previous reports, OGF has been identified as the opioid peptide that binds to OGFr and activates a response signal in SCCHN (5). This peptide has been found to be produced and secreted by a variety of cells so that the elements regulating cell proliferation are dependent on the cell itself $(5,9)$. In the 
present study, a test of this ligand-dependent axis was made in clonal lines overexpressing OGFr by subjecting these cells in culture to an antibody to OGF. All groups of cells (WT, $\mathrm{EV}$, and clonal OGFr overexpressing cells) exposed to the antibody to OGF responded with an increase in cell number compared to no treatment with antibody. In fact, clonal cells had an increase in cell number more than 2-fold greater than in the parental cell line or the empty vector. Thus, cells overexpressing OGFr reacted in the predicted manner to the depletion of OGF from the cultures, perhaps with a supersensitive reaction due to the growth suppressive effects of extra OGF receptors. These data are consistent with the postulate that the OGF-OGFr axis is in an autocrine loop and vital to the regulation of SCCHN, with disturbances of peptide or receptor markedly altering homeostatic equilibrium and bringing about changes in cell replication.

The finding that OGFr is activated by OGF begs the question of whether the changes seen in growth by clonal lines were due, wholly or in part, to increases in OGF levels because of a compensatory mechanism related to the abundance of the receptor. A number of observations argue that this is not the case. First, if OGF increased in proportion to the abundance of OGF receptors, then one would predict that clonal lines with the greatest number of receptors would have the highest levels of opioids and the largest decreases in growth. However, as mentioned earlier, no correlation could be found between factors such as the number of OGF receptors and growth effects. Second, previous experiments with opioid receptor blockade using opioid antagonists have shown an upregulation of opioid peptides, so that an abundance of opioid agonists would be expected to result in a downregulation, rather than an upregulation, of opioid levels. Therefore, although there is a need to examine OGF levels in cultures of clonal cell lines with amplification of OGFr, it would not appear that changes in OGF values because of OGFr overexpression are responsible for growth alterations.

The present discoveries on the effects of additional OGF receptors in SCCHN cells with respect to cell proliferation complement observations in previous studies regarding modulating OGF-OGFr interactions. Antisense technology which attenuates OGFr levels has revealed marked increases in the number of human neuroblastoma and rat intestinal epithelial cells compared to control levels $(9,25)$, whereas blockade of OGF-OGFr interactions with opioid antagonists such as naltrexone also elevates cell number including SCCHN cells such as SCC-1 (5). These findings are consistent with the present results showing that overexpression of OGFr decreases the number of SCC-1 cells. Our data are also consonant with reports that transient transfection of OGFr cDNA into rat corneal epithelial cells in vivo using a gene gun depresses DNA synthesis (26) and wound healing (27). We now show that stable transfections of OGFr cDNA can markedly inhibit the proliferation of cancer cells under in vitro conditions. Whether these SCCHN cells with an overexpression of OGFr also have delays in growth under an in vivo environment remains to be determined.

Clinically, the OGF-OGFr axis has been detected using receptor binding, immunohistochemistry, and Western blotting in biopsy and surgical specimens of human SCCHN $(4,10)$. Human SCCHN transplanted into nude mice has revealed that the OGF-OGFr axis is functional as well $(12,14,15)$. However, compared to normal epithelium, there were 9-fold fewer OGFr binding sites in SCCHN tissue, and 5-fold less protein consistent with the hypothesis that disruption of OGFr function may be a contributing etiological factor in SCCHN. Tumor margins, diagnosed as 'normal' by pathology, had intermediate levels of binding and protein between tumor and normal samples. Given that SCCHN is the sixth most common cancer in the world and the seventh in mortality, and that the survival rate for this neoplasia has not improved substantially in decades (2), strategies for treatment of this cancer are needed. In the present study, we found that introduction of additional OGFr into SCCHN has a dramatic effect on cell number. Therefore, gene therapy (e.g., gene gun) to reinstate OGFr with functional effects could provide a useful treatment for inhibiting tumor progression.

\section{Acknowledgements}

Supported by a grant from Philip Morris USA Inc. and Philip Morris International.

\section{References}

1. Jemal A, Siegel R, Ward E, Murray T, Xu J, Smigal C and Thun MJ: Cancer statistics, 2006. CA Cancer J Clin 56: 106-130, 2006.

2. Parkin DM, Pisani P and Ferlay J: Global cancer statistics. CA Cancer J Clin 49: 33-64, 1999.

3. Carew JF and Shah JP: Advances in multimodality therapy for laryngeal cancer. CA Cancer J Clin 48: 211-228, 1998.

4. Levin RJ, Wu Y, McLaughlin PJ and Zagon IS: Expression of the opioid growth factor, [Met $\left.{ }^{5}\right]$-enkephalin, and the zeta opioid receptor in head and neck squamous cell carcinoma. Laryngoscope 107: 335-339, 1997.

5. McLaughlin PJ, Levin RJ and Zagon IS: Regulation of human head and neck squamous cell carcinoma growth in tissue culture by opioid growth factor. Int J Oncol 14: 991-998, 1999.

6. McLaughlin PJ, Levin RJ and Zagon IS: The opioid growth factor receptor in human head and neck squamous cell carcinoma. Int J Mol Med 5: 191-196, 2000.

7. Zagon IS, Roesener CD, Verderame MF, Ohlsson-Wilhelm BM, Levin RJ and McLaughlin PJ: Opioid growth factor regulates the cell cycle of human neoplasias. Int J Oncol 17: 1053-1061, 2000.

8. Zagon IS, Verderame MF, Allen SS and McLaughlin PJ: Cloning, sequencing, chromosomal location, and function of a cDNA encoding the opioid growth factor receptor (OGFr) in humans. Brain Res 856: 75-83, 2000.

9. Zagon IS, Verderame MF and McLaughlin PJ: The biology of the opioid growth factor receptor (OGFr). Brain Res Rev 38: 351-376, 2002.

10. McLaughlin PJ, Stack BC, Levin RJ, Fedok F and Zagon IS: Defects in the OGF receptor (OGFr) in human squamous cell carcinoma of the head and neck. Cancer 97: 1701-1710, 2003.

11. Zagon IS and McLaughlin PJ: Opioids and the apoptotic pathway in human cancer cells. Neuropeptides 37: 79-88, 2003.

12. McLaughlin PJ, Levin RJ and Zagon IS: Opioid growth factor (OGF) inhibits the progression of human squamous cell carcinoma of the head and neck transplanted into nude mice. Cancer Lett 199: 209-217, 2003.

13. Zagon IS and McLaughlin PJ: Opioid growth factor (OGF) inhibits anchorage-independent growth in human cancer cells. Int J Oncol 24: 1443-1148, 2004.

14. McLaughlin PJ, Stack BC, Braine KM, Ruda JD and Zagon IS: Opioid growth factor inhibition of a human squamous cell carcinoma of the head and neck in nude mice: Dependency on the route of administration. Int J Oncol 24: 227-232, 2004.

15. Jaglowski JR, Zagon IS, Stack BC, Verderame MF, Leure-duPree AE, Manning JD and McLaughlin PJ: Opioid growth factor enhances tumor growth inhibition and increases the survival of paclitaxel-treated mice with squamous cell carcinoma of the head and neck. Cancer Chemother Pharmacol 56: 97-104, 2005. 
16. McLaughlin PJ, Jaglowski JR, Verderame MF, Stack BC, Leure-duPree AE and Zagon IS: Enhanced growth inhibition of squamous cell carcinoma of the head and neck by combination therapy of paclitaxel and opioid growth factor. Int J Oncol 26: 809-816, 2005.

17. Zagon IS and McLaughlin PJ: Opioid growth factor, opioids, and differentiation of human cancer cells. Neuropeptides 39: 495-505, 2005.

18. Cheng F, Zagon IS, Verderame MF and McLaughlin PJ: OGFOGFr axis and its inhibitory actions on cell cycle progression of head and neck cancer cell line SCC1. Mol Biol Cell 16: 77, 2005.

19. McLaughlin PJ and Zagon IS: Progression of squamous cell carcinoma of the head and neck is associated with downregulation of the opioid growth factor receptor. Int J Oncol 28: 1577-1583, 2006.

20. Zagon IS, Wu Y and McLaughlin PJ: Opioid growth factor inhibits DNA synthesis in mouse tongue epithelium in a circadian rhythm-dependent manner. Am J Physiol 267: R645R652, 1994.

21. Zagon IS, Wu Y and McLaughlin PJ: The opioid growth factor, $\left[\mathrm{Met}^{5}\right]$-enkephalin, and the $\xi$ (zeta) opioid receptor are present in human and mouse skin and tonically act to inhibit DNA synthesis in the epidermis. J Invest Dermatol 106: 490-497, 1996.
22. Zagon IS, Ruth TB, Leure-duPree AE, Sassani JW and McLaughlin PJ: Immunoelectron microscopic localization of the opioid growth factor receptor (OGFr) and OGF in the cornea. Brain Res 967: 37-47, 2003.

23. Zagon IS, Ruth TB and McLaughlin PJ: Nucleocytoplasmic distribution of opioid growth factor (OGF) and its receptor (OGFr) in tongue epithelium. Anat Rec 282A: 24-37, 2005.

24. Krause CJ, Carey TE, Ott RW, Hurbis C, McClatchey KD and Regezi JA: Human squamous cell carcinoma. Arch Otolaryngol 107: 703-710, 1981 .

25. Zagon IS, Verderame MF, Allen SS and McLaughlin PJ: Cloning, sequencing, expression, and function of a cDNA encoding a receptor for the opioid growth factor, [Met ${ }^{5}$ enkephalin. Brain Res 849: 147-154, 1999.

26. Zagon IS, Sassani JW, Verderame MF and McLaughlin PJ: Particle-mediated gene transfer of OGFr cDNA regulates cell proliferation of the corneal epithelium. Cornea 24: 614-619, 2005.

27. Zagon IS, Sassani JW, Malefyt KJ and McLaughlin PJ: Particlemediated gene transfer of OGFr cDNA regulates corneal repair. Arch Ophthalmol 124: 1620-1624, 2006. 